\title{
Habilidade Competitiva de Cultivares de Cevada Convivendo COM AZEVÉM ${ }^{1}$
}

\author{
Competitive Ability of Barley Cultivars Against Ryegrass
}

\author{
GALON, L. ${ }^{2}$, TIRONI, S.P. ${ }^{3}$, ROCHA, P.R.R. ${ }^{3}$, CONCENÇO, G..$^{4}$, SILVA, A.F. ${ }^{3}$, VARGAS, L. ${ }^{5}$, \\ SILVA, A.A. ${ }^{6}$, FERREIRA, E.A. ${ }^{7}$, MINELLA, E. ${ }^{5}$, SOARES, E.R. ${ }^{8}$ e FERREIRA, F.A. ${ }^{6}$
}

\begin{abstract}
RESUMO - A determinação da habilidade competitiva de cultivares de cevada com plantas daninhas torna-se relevante para a adoção do método de manejo cultural; desse modo, podemse diminuir os custos de produção, bem como os impactos ambientais causados por outros métodos de manejo, como o químico. Este trabalho comparou as habilidades competitivas relativas de três cultivares de cevada e um biótipo de azevém. Foram realizados experimentos em casa de vegetação na estação de crescimento 2008/09, utilizando-se delineamento experimental de blocos casualizados, com quatro repetições. Os tratamentos foram arranjados em série de substituição e constituíram-se de cinco proporções de plantas de cevada e do azevém competidor com a cultura: 100:0, 75:25, 50:50, 25:75 e 0:100. A cevada foi representada pelos cultivares BRS Greta, BRS Elis e BRS 225, e o competidor, pelo azevém. A análise da competitividade foi efetuada por meio de diagramas aplicados a experimentos substitutivos, mais uso de indices de competitividade relativa. As variáveis estudadas foram: afilhamento, estatura, área foliar e massa da matéria seca da parte aérea das plantas. O azevém afetou o afilhamento, a área foliar e a massa da matéria seca da parte aérea de plantas dos cultivares de cevada BRS Greta, BRS Elis e BRS 225, demonstrando grande habilidade competitiva com a cultura pelos recursos disponiveis no meio. Entre os cultivares de cevada avaliados, BRS Elis foi o mais competitivo na presença do azevém, que é uma das espécies daninhas que necessitam de controle mesmo quando presente em baixas proporções na cultura da cevada.
\end{abstract}

Palavras-chave: cereais de inverno, Hordeum vulgare, Lolium multiflorum, características morfofisiológicas.

\begin{abstract}
Characterization of the competitive ability of barley varieties against weed species is relevant for the adoption of the cultural method of weed control; thus, it is possible to reduce both the production costs and environmental impacts caused by other management methods, including the use of chemicals. This work assessed the competitive ability of barley varieties against ryegrass. Trials were installed under greenhouse conditions at the 2008/2009 cropping season, in a completely randomized block design, with four replications. Treatments were arranged in a substitution series design constituted by five proportions of plants of both species: 100:0; 75:25; 50:50; 25:75; and 0:100. Barley varieties BRS Greta, BRS Elis and BRS 225 were tested against ryegrass as the competitor. The competitive analysis was carried out through diagrams applied to the substitutive design, plus determination of relative competitiveness indexes. Plant height, tillering, leaf area and shoot dry mass were evaluated. The presence of ryegrass reduced tillering, leaf area and dry mass accumulation for all varieties of barley tested, showing to be an aggressive competitor. Among the barley varieties tested, BRS Elis showed the highest competitive ability against ryegrass. Ryegrass requires the adoption of control techniques even when present at low proportions in the field.
\end{abstract}

Keywords: winter cereals, Hordeum vulgare, Lolium multiflorum, morphophysiological characteristics.

1 Recebido para publicação em 18.2.2011 e aprovado em 3.5.2011.

2 Engo-Agroo., D.Sc., Prof., Universidade Federal do Pampa - UNIPAMPA, Campus Itaqui, Rua Luiz Joaquim de Sá Britto, s/n, 97650-000 Itaqui-RS, <leandrogalon@unipampa.edu.br>; ${ }^{3}$ Engo-Agr ${ }^{\circ}$., Doutorando, Dep. de Fitotecnia, Universidade Federal de Viçosa - DFT/UFV, Bolsista do CNPq; ${ }^{4}$ Engo-Agr ${ }^{\circ}$., D.Sc., Pesquisador em Herbologia, Embrapa Agropecuária Oeste - CPAO, Dourados-MS, Brasil; ${ }^{5}$ Eng$^{0}-$ Agr $^{0}$., D.Sc., Pesquisador, Embrapa Trigo, Passo Fundo; ${ }^{6}$ Eng $^{0}-$ Agr $^{0}$., D.Sc., Professor, DFT/UFV, Bolsista em Produtividade do CNPq; ${ }^{7}$ Engo-Agro․ , D. Sc., Bolsista PNPD, Faculdade de Ciências Agrárias, Universidade Federal dos Vales do Jequitinhonha e Mucuri - UFVJM, Diamantina-MG; ${ }^{8}$ Aluno de Agronomia, Faculdade da Amazônia.

Planta Daninha, Viçosa-MG, v. 29, n. 4, p. 771-781, 2011 


\section{INTRODUÇÃO}

A cevada (Hordeum vulgare) foi uma das primeiras espécies domesticadas pelo homem para a sua alimentação. Pela ampla adaptabilidade ecológica e por ser matéria-prima na fabricação de cerveja, destaca-se entre as graníferas mais produzidas ao longo dos tempos, ocupando a quinta posição em termos de importância econômica no mundo (FAO, 2011). A produção brasileira está concentrada na região Sul. O Rio Grande do Sul (RS) participa com $40 \%$ da cevada produzida no País, e esse Estado apresenta rendimento médio de $2.432 \mathrm{~kg} \mathrm{ha}^{-1}, 15 \%$ menor que a média nacional (CONAB, 2011).

As plantas daninhas alteram significativamente a produtividade de grãos de cevada, podendo comprometer, além do rendimento de grãos, a qualidade da matériaprima destinada à indústria. Entre as espécies que infestam a cevada, destaca-se o azevém (Lolium multiflorum), altamente competitivo pelos recursos disponíveis no meio; em muitos casos, no Estado do RS é resistente a herbicidas, como o glyphosate. Essa espécie compete pelos recursos disponiveis no meio, como água, luz, $\mathrm{CO}_{2}$ e nutrientes, o que altera a expressão do potencial produtivo da cultura e também dificulta a expansão da área cultivada, além de causar interferência no crescimento e desenvolvimento e reduzir a produtividade de grãos (Nunes et al., 2007).

O azevém é uma espécie que se adapta bem a solos de baixa e média fertilidade, com boa resposta à adubação e fácil dispersão; por isso, está presente e caracteriza-se como planta daninha em praticamente todas as lavouras de inverno (Kissmann, 1997). Por pertencer à mesma família botânica da cevada e apresentar características morfofisiológicas semelhantes, existem dificuldades para o seu controle químico, em razão da seletividade para a cultura e da eficácia do produto.

Poucos são os estudos sobre a competição de plantas daninhas com cultivares de cevada. A maioria dos artigos está relacionada com a interferência do azevém na cultura do trigo. $\mathrm{O}$ azevém, ao competir com trigo durante todo o ciclo, ocasionou redução de $83 \%$ (Holman et al., 2004) ou cerca de 60\% (Agostinetto et al., 2008) da produtividade média de grãos.
A cevada, quando em convivência com comunidade de plantas daninhas durante todo o ciclo, teve a produtividade de grãos reduzida em 25\% (Richardson, 1980) e 71\% (Scursoni \& Satorre, 2005).

Os programas de melhoramento genético têm procurado desenvolver cultivares que, com pequeno porte e pouco crescimento vegetativo, apresentem elevado acúmulo de fotoassimilados nas sementes. Com frequência, esse acréscimo na produtividade econômica da espécie cultivada é acompanhado por decréscimo no potencial competitivo (Pitelli, 1985). Em decorrência disso, as plantas daninhas frequentemente levam vantagem competitiva sobre as cultivadas sob condições semelhantes (Bianchi et al., 2006). No entanto, para que ocorra competição, há necessidade de sobreposição suficiente dos nichos dos indivíduos que competem entre si, de modo que eles passem a utilizar os mesmos recursos do ambiente (Cousens, 1991).

Estudos sobre competitividade de culturas com plantas daninhas permitem desenvolver estratégias para seu manejo, pois podem definir as características que confiram maior habilidade competitiva às culturas (Fleck et al., 2003). Cultivares com maiores velocidades de incremento de área foliar, estatura, massa da matéria seca da parte aérea, maior cobertura do solo e interceptação de luz pelo dossel apresentaram maior habilidade competitiva com as plantas daninhas (Fleck et al., 2003).

Dos fatores ligados à comunidade infestante, a população de plantas pode ser considerada um dos mais importantes, de tal forma que, quanto maior for a população da comunidade infestante, maior será a quantidade de indivíduos que disputam os mesmos recursos do meio; desse modo, a competição entre as plantas poderá ser mais intensa. Em nivel de lavoura, a população das plantas cultivadas geralmente é constante, ao passo que a população das plantas daninhas varia de acordo com a quantidade de sementes depositadas no banco do solo ou de acordo com o nivel de infestação e as condições encontradas no local, obtendo-se, assim, variação na proporção entre as espécies daninhas e a cultura. Assim, nos estudos de competição, não basta avaliar somente a população de plantas no processo 
competitivo, mas também é importante verificar a influência da variação na proporção entre as espécies (Christoffoleti \& Victória Filho, 1996).

Objetivou-se com este trabalho comparar as habilidades competitivas dos cultivares de cevada BRS Greta, BRS Elis e BRS 225 entre si e em relação ao azevém.

\section{MATERIAL E MÉTODOS}

Experimentos foram conduzidos em casa de vegetação, na estação de cultivo 2008/09. Os ensaios foram alocados em vasos plásticos com capacidade volumétrica de $6 \mathrm{~L}$, preenchidos com solo previamente corrigido quanto à sua fertilidade, de acordo com as recomendações técnicas para a cultura da cevada (EMBRAPA, 2005/06).

O delineamento experimental foi o de blocos casualizados, com quatro repetições. Os competidores testados incluíram os cultivares de cevada BRS Greta, BRS Elis e BRS 225 e um biótipo de azevém.

Em experimento preliminar, tanto para a cevada quanto para o azevém em monocultivo, o objetivo foi determinar a população de plantas em que a produção final se torna constante. Utilizaram-se populações de 1, 2, 4, 8, 16, 24, 32 e 40 plantas por vaso (equivalente a 26,52 , 104, 208, 416, 624, 832 e 1.040 plantas $\mathrm{m}^{-2}$, respectivamente). A produção final constante foi obtida com população de 20 plantas por vaso para todos os cultivares testados em competição com o azevém, o que equivaleu a 520 plantas $\mathrm{m}^{-2}$ (dados não apresentados).

Outros três experimentos foram instalados para avaliar a competitividade das variedades de cevada BRS Greta, BRS Elis e BRS 225 com plantas de azevém, todos conduzidos em série de substituição, nas diferentes combinações dos cultivares e do biótipo da espécie daninha, variando-se as proporções relativas de plantas por vaso $(0: 20,5: 15,10: 10,15: 5,20: 0)$, mantendo-se constante a população total de plantas (20 plantas por vaso). Para estabelecer as populações desejadas em cada tratamento e obter uniformidade das plântulas, as sementes foram previamente semeadas em bandejas, sendo posteriormente transplantadas para os vasos.
Aos 50 dias após a emergência (DAE), avaliaram-se as variáveis: afilhamento (Afi), estatura (Est), área foliar (AF) e massa da matéria seca da parte aérea (MS) das plantas. $\mathrm{O}$ Afi foi obtido pela contagem do número de afilhos. Determinou-se a Est pela mensuração da distância da base até a extremidade da folha-bandeira. A quantificação da AF foi realizada com auxílio de integrador eletrônico, utilizando as folhas das plantas colhidas para avaliação da MS, em todas as plantas presentes nos vasos. Para se obter a MS, as plantas foram seccionadas ao nivel do solo e a secagem do material foi efetuada em estufa de circulação forçada de ar, aquecida a $60 \pm 5{ }^{\circ} \mathrm{C}$, até a uniformidade das massas secas.

Os dados foram analisados pelo método da análise gráfica da variação ou produtividade relativa (Roush et al., 1989; Cousens, 1991; Bianchi et al., 2006). O referido procedimento, também conhecido como método convencional para experimentos substitutivos, consiste na construção de um diagrama tendo por base as produtividades ou variações relativas $(P R)$ e totais (PRT). Quando o resultado da PR for uma linha reta, significa que as habilidades das espécies são equivalentes. Caso a PR resulte em linha côncava, indica que existe prejuízo no crescimento de uma ou de ambas as espécies. Ao contrário, se a PR mostrar linha convexa, há benefício no crescimento de uma ou de ambas as espécies. Quando a PRT for igual à unidade (1) (linha reta), ocorre competição pelos mesmos recursos; se ela for superior a 1 (linha convexa), a competição é evitada; caso a PRT seja menor que 1 (linha côncava), há prejuízo mútuo para o crescimento (Cousens, 1991).

Determinaram-se ainda os indices de competitividade relativa (CR), coeficiente de agrupamento relativo (K) e agressividade (A). A CR representa o crescimento comparativo dos cultivares de cevada $X$ em relação ao competidor azevém Y; $\mathrm{K}$ indica a dominância relativa de uma espécie sobre outra; e A aponta qual das espécies é mais agressiva. Assim, os indices $\mathrm{CR}, \mathrm{K}$ e A indicam qual espécie se manifesta mais competitiva, e sua interpretação conjunta indica com maior segurança a competitividade das espécies (Cousens, 1991). Os cultivares de cevada $X$ são mais competitivos que o azevém $\mathrm{Y}$ quando $\mathrm{CR}>1, \mathrm{~K}_{\mathrm{x}}>\mathrm{K}_{\mathrm{y}}$

Planta Daninha, Viçosa-MG, v. 29, n. 4, p. 771-781, 2011 
e A > 0; por outro lado, o azevém Y é mais competitivo que os cultivares de cevada $\mathrm{X}$ quando $\mathrm{CR}<1, \mathrm{~K}_{\mathrm{x}}<\mathrm{K}_{\mathrm{y}}$ e $\mathrm{A}<0$ (Hoffman \& Buhler, 2002). Para calcular esses indices, foram usadas as proporções 50:50 das espécies envolvidas no experimento (cevada e azevém), utilizando-se as seguintes equações, conforme sugerido por Cousens \& O'Neill (1993): $\mathrm{CR}=\mathrm{PR}_{\mathrm{x}} / \mathrm{PR}_{\mathrm{y}} ; \mathrm{K}_{\mathrm{x}}=\mathrm{PR}_{\mathrm{x}} /\left(1-\mathrm{PR}_{\mathrm{x}}\right) ; \mathrm{K}_{\mathrm{y}}=\mathrm{PR}_{\mathrm{y}} /\left(1-\mathrm{PR}_{\mathrm{y}}\right)$; $\mathrm{A}=\mathrm{PR}_{\mathrm{x}}-\mathrm{PR}_{\mathrm{y}}$.

O procedimento de análise estatística da produtividade ou variação relativa incluiu o cálculo das diferenças para os valores de PR (DPR) obtidos nas proporções de 25, 50 e 75\%, em relação aos valores pertencentes à reta hipotética nas respectivas proporções, quais sejam: 0,25, 0,50 e 0,75 para PR (Bianchi et al., 2006). Utilizou-se o teste t para testar as diferenças relativas aos índices DPR, PRT, CR, K e A (Roush et al., 1989; Hoffman \& Buhler, 2002). Considerou-se, como hipótese nula para testar as diferenças de DPR e A, que as médias fossem iguais a zero $\left(\mathrm{H}_{\mathrm{o}}=0\right)$; para PRT e CR, que elas fossem iguais a $1\left(H_{o}=1\right)$; e para $\mathrm{K}$, que as médias das diferenças entre $\mathrm{K}_{\mathrm{x}}$ e $\mathrm{K}_{\mathrm{y}}$ fossem iguais a zero $\left[\mathrm{H}_{\mathrm{o}}=\left(\mathrm{K}_{\mathrm{x}}-\mathrm{K}_{\mathrm{y}}\right)=0\right]$. $\mathrm{O}$ critério para considerar as curvas de PR e PRT diferentes das retas hipotéticas foi que, no mínimo em duas proporções, ocorressem diferenças significativas pelo teste $\mathrm{t}$ (Bianchi et al., 2006). Do mesmo modo, considerou-se, para os índices $\mathrm{CR}, \mathrm{K}$ e $\mathrm{A}$, a existência de diferenças em competitividade quando, no mínimo em dois deles, houvesse diferença significativa pelo teste $t$.

Os resultados obtidos para Afi, Est, AF e MS, expressos em valores médios por tratamento, foram submetidos à análise de variância (SAS). Quando o teste F da análise indicou significância, as médias dos tratamentos foram comparadas pelo teste de Dunnett, considerando-se as monoculturas como testemunhas nessas comparações. Em todas as análises estatísticas efetuadas, adotou-se como probabilidade de erro $\mathrm{p} \leq 0,05$.

\section{RESULTADOS E DISCUSSÃO}

Os resultados gráficos demonstram, para as combinações de plantas dos cultivares de cevada BRS Greta, BRS Elis ou BRS 225 com o biótipo de azevém (competidor), que os três cultivares apresentaram semelhanças quanto à competição com a espécie daninha, ocorrendo diferenças significativas para as variáveis Afi, Est, AF e MS nas proporções de plantas testadas. Com relação à PRT, houve diferenças significativas entre os valores esperados e estimados para todas as variáveis estudadas, tendo estas apresentado valores médios próximos ou maiores que 1 somente para a variável Est, ao passo que as demais apresentaram valores inferiores a 1 , em todas as combinações (Figuras 1, 2, 3 e 4; Tabela 1).

A presença de linhas côncavas em todas as simulações para as variáveis Afi, AF e MS indicou que ocorreu competição pelos mesmos recursos do ambiente, havendo prejuízo mútuo para o crescimento tanto da cultura quanto do competidor (Figuras 1, 2, 3 e 4). Segundo Harper (1977), quando PRT < 1, há antagonismo mútuo entre as espécies que estão competindo pelos recursos do ambiente. Ressaltase que para Est não se observaram linhas côncavas e sim convexas, ou seja, os desvios dos valores observados foram maiores que os estimados; nesse caso, houve benefício de crescimento para a cultura e prejuízo para o competidor nas simulações testadas (Figura 1). Existe a hipótese de que nesse caso a competição possa ser evitada, pelo fato de o suprimento de recursos superar a demanda ou porque as espécies possuem diferentes necessidades pelos recursos do ambiente. Outra hipótese também aceita é de que as plantas cultivadas - no caso, os cereais de inverno -, quando em competição por luz, aumentam o investimento de fotoassimilados na formação de colmos mais longos, ou seja, ocorre estiolamento na tentativa de captar mais luminosidade, com menor investimento de energia para o perfilhamento, desenvolvimento de área foliar e de massa seca e crescimento radicular; até mesmo a produtividade de grãos pode ser afetada, pois a planta investe mais energia no órgão que estiver com maior déficit nutricional, em contraponto aos demais. Resultados semelhantes foram observados por Agostinetto et al. (2008) e Rigolli et al. (2008), trabalhando com a cultura do trigo competindo com azevém ou nabo, os quais relataram que essa estratégia geralmente é adotada por plantas cultivadas quando a luz é o principal recurso limitado na comunidade (Almeida \& Mundstock, 2001). 

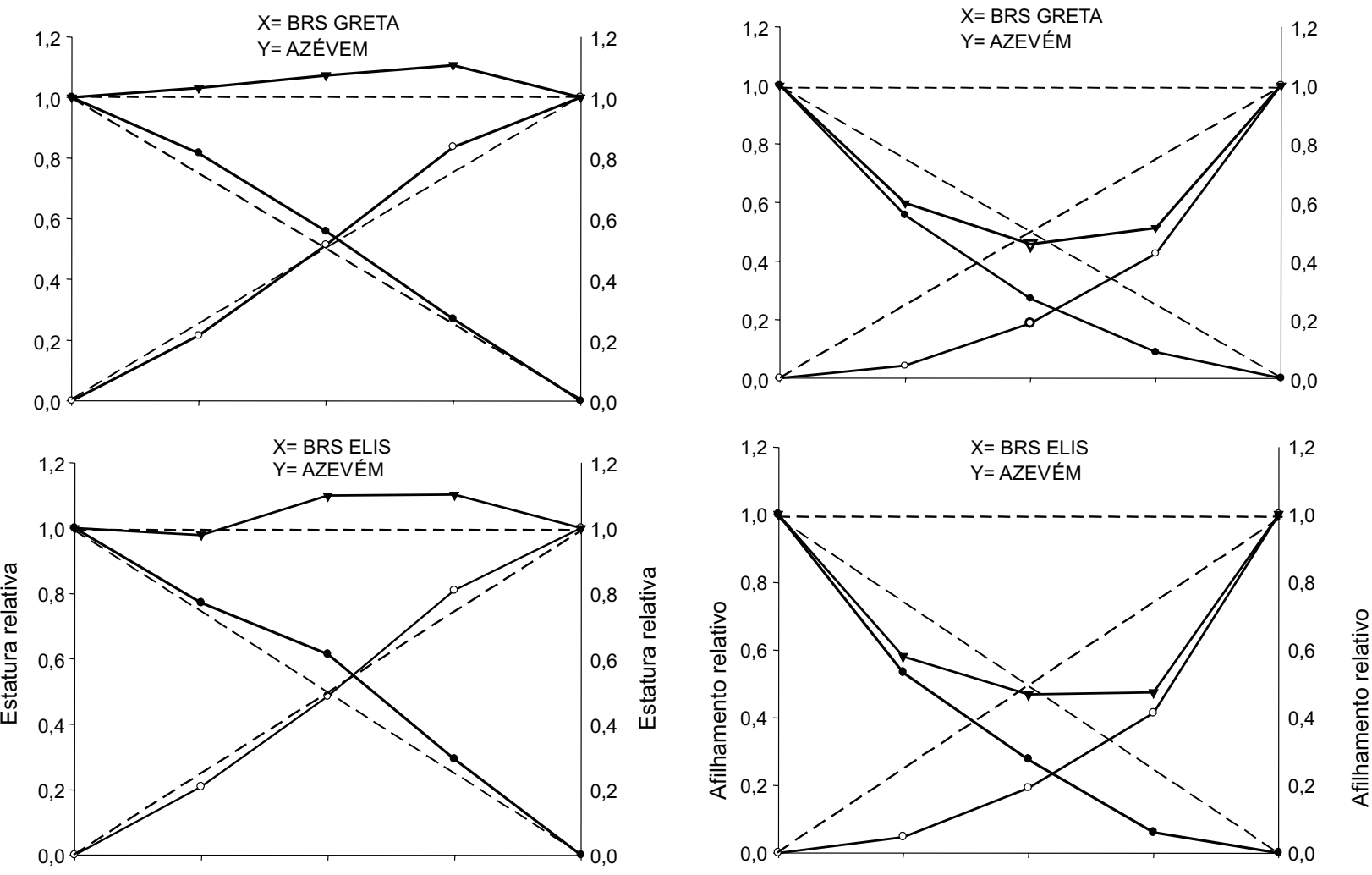

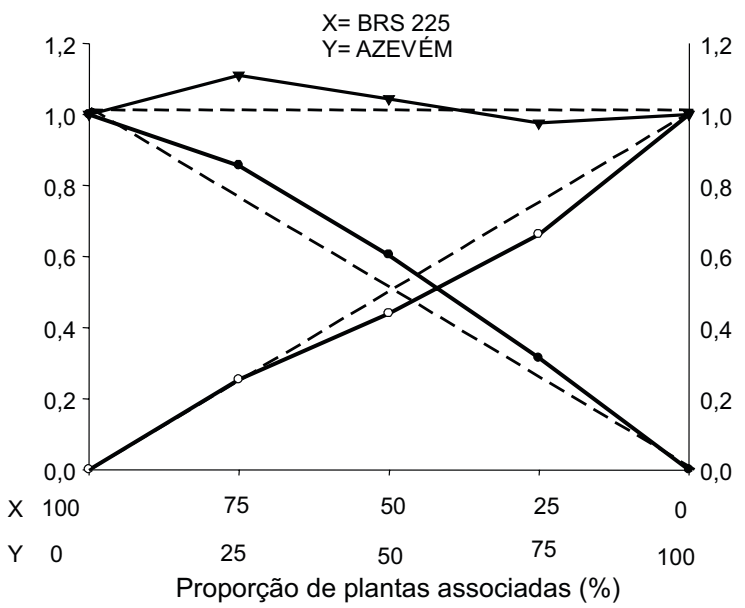

Figura 1 - Diagramas da estatura relativa de plantas. (•) Estatura relativa do cultivar de cevada (X), (o) estatura do competidor $(\mathrm{Y})$ e $(\boldsymbol{\nabla})$ estatura relativa total (AFRT).

$\mathrm{Na}$ análise gráfica das combinações de plantas dos cultivares BRS Greta, BRS Elis ou BRS 225 e do biótipo de azevém, para as variáveis testadas, os desvios observados das retas da $P R$, em relação às retas esperadas, são representados por linhas côncavas para a cultura e para o competidor, demonstrando que ambos competem pelos mesmos recursos do

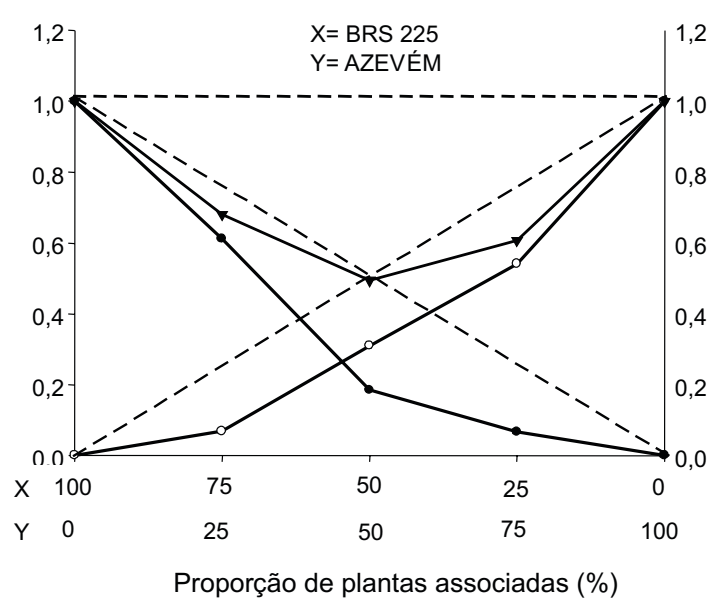

Figura 2 - Diagramas do afilhamento relativo de plantas (•)Afilhamento do cultivar de cevada (X), (o) afilhamento do competidor $(\mathrm{Y})$ e ( $\boldsymbol{\nabla})$ afilhamento relativo total.

ambiente (Figuras 2, 3 e 4). Considerando que para haver significância pelo menos duas proporções de plantas devem diferir (Bianchi et al., 2006), foram verificadas diferenças entre as retas estimadas e esperadas em todas as variáveis estudadas e em todas as proporções de plantas, exceto Est na proporção de 75:25 para o cultivar BRS Greta e em todas as 
proporções de plantas para a BRS 225 ao competirem com o azevém (Figuras 1, 2, 3 e 4; Tabela 1).

De modo geral, os cultivares de cevada BRS Greta, BRS Elis e BRS 225 apresentaram maior crescimento relativo do que o azevém
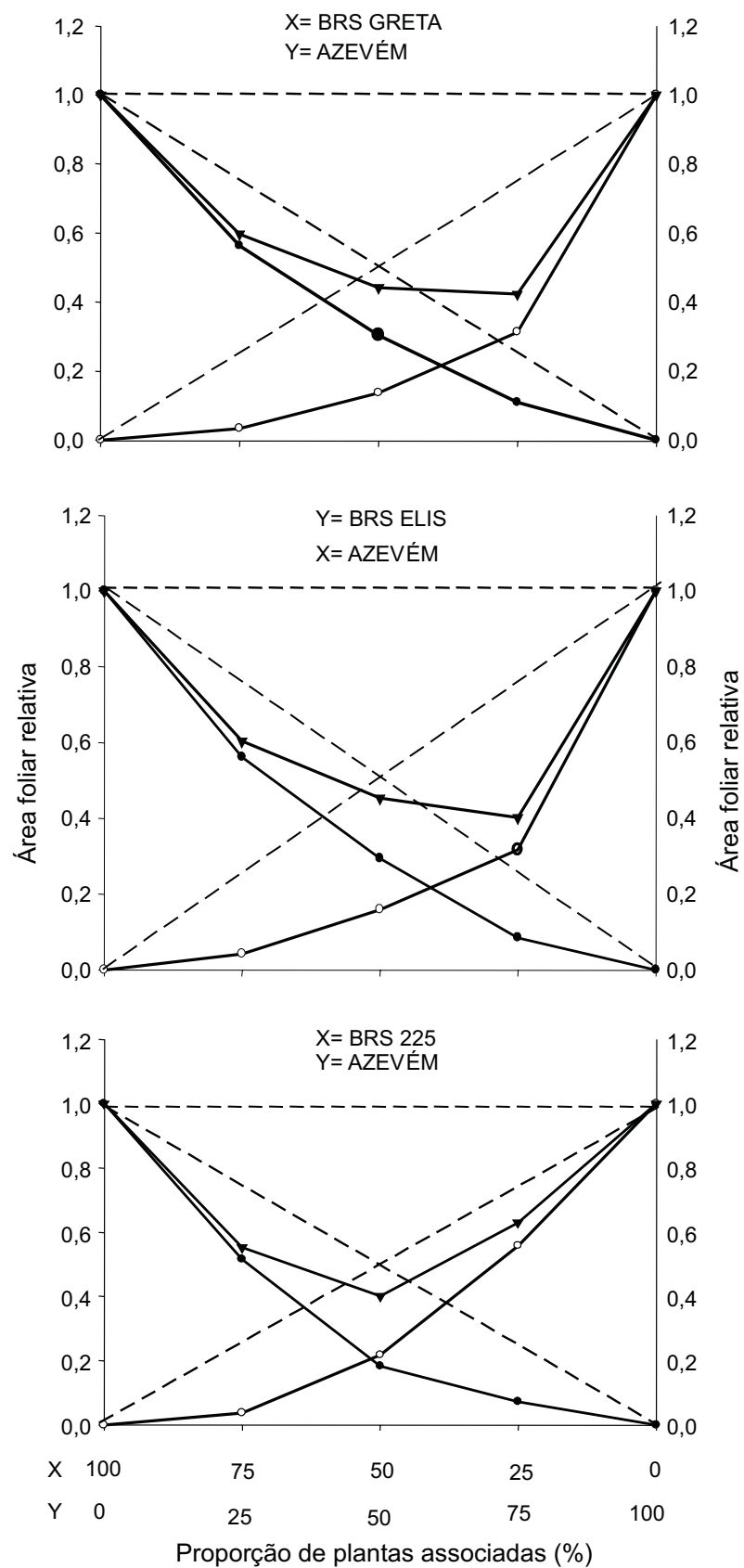

Figura 3 - Área foliar relativa de plantas. (•) Área foliar do cultivar de cevada $(\mathrm{X}),(\mathrm{o})$ área foliar do competidor $(\mathrm{Y}) \mathrm{e}$ $(\boldsymbol{\nabla})$ área foliar relativa total (AFRT) em todas as proporções de plantas testadas (Figuras 1, 2, 3 e 4; Tabela 1), porém contribuíram pouco para a PRT. A provável causa de a cevada apresentar maior crescimento pode estar relacionada à estatura de plantas, tornando-se mais eficiente na captura da radiação solar e impondo sombreamento ao
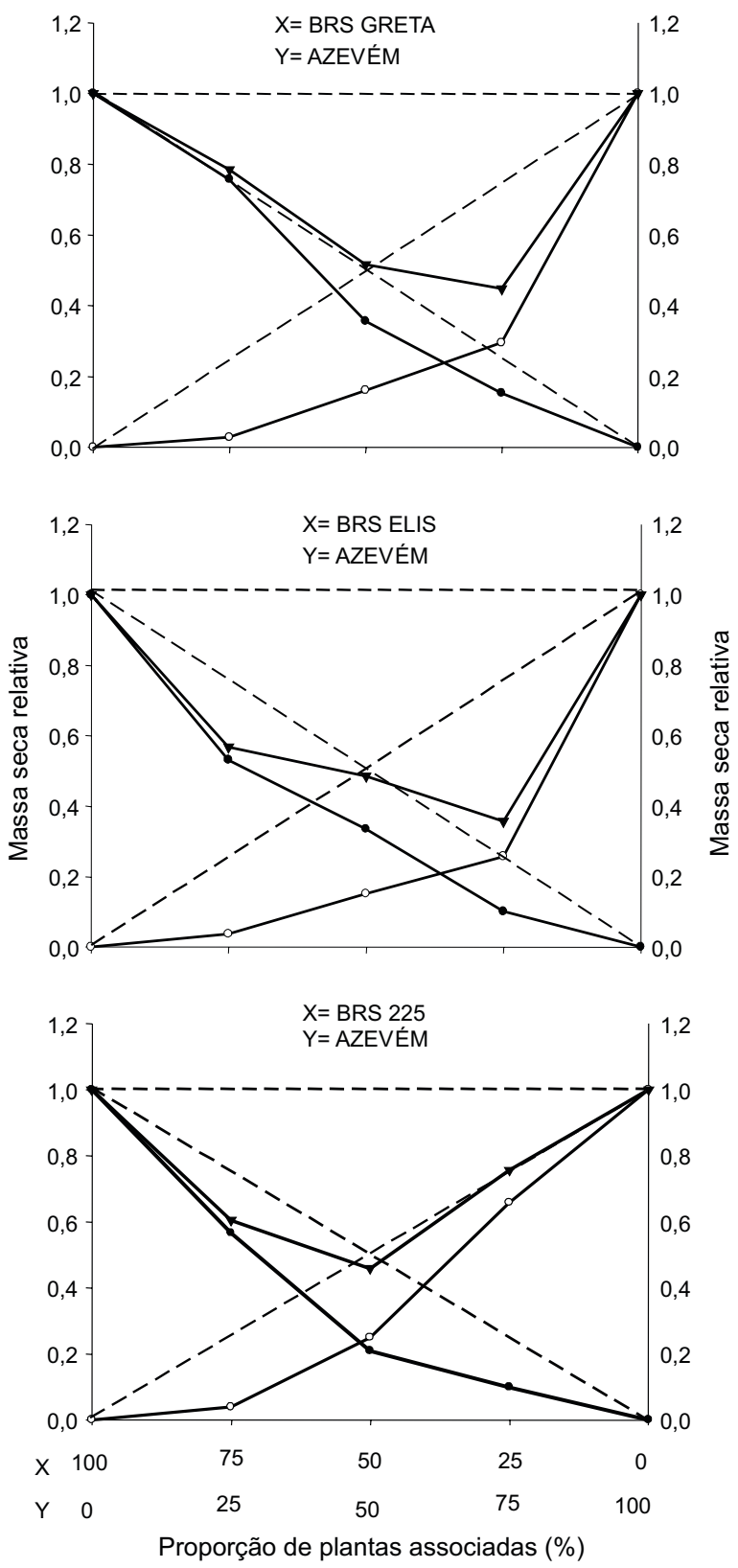

Figura 4 - Massa da matéria seca da parte aérea relativa de plantas. $(\bullet)$ Massa da matéria seca da parte aérea do cultivar de cevada $(X),(0)$ massa da matéria seca da parte aérea do competidor $(\mathrm{Y})$ e $(\boldsymbol{\nabla})$ massa da matéria seca da parte aérea relativa total (AFRT) 
Tabela 1 - Diferenças relativas para as variáveis afilhamento, estatura, área foliar e massa da matéria seca aérea dos cultivares de cevada BRS Greta, BRS Elis e BRS 225 ou de azevém, aos 50 dias após a emergência das plantas

\begin{tabular}{|c|c|c|c|}
\hline \multirow[t]{2}{*}{ Variável } & \multicolumn{3}{|c|}{$\begin{array}{l}\text { Proporções de plantas associadas } \\
\text { (cevada: competidor) }\end{array}$} \\
\hline & $75: 25$ & $50: 50$ & $25: 75$ \\
\hline \multicolumn{4}{|c|}{ Afilhamento } \\
\hline BRS Greta & $-0,14( \pm 0,01)$ & $-0,32( \pm 0,01)$ & $-0,18( \pm 0,01)$ \\
\hline Azevém & $-0,18( \pm 0,01)$ & $-0,19( \pm 0,02)$ & $-0,21( \pm 0,02)$ \\
\hline Total & $0,68( \pm 0,01)$ & $0,49( \pm 0,01)$ & $0,61( \pm 0,02)$ \\
\hline BRS Elis & $-0,22( \pm 0,03)$ & $-0,22( \pm 0,01)$ & $-0,19( \pm 0,01)$ \\
\hline Azevém & $-0,20( \pm 0,01)$ & $-0,31( \pm 0,01)$ & $-0,34( \pm 0,01)$ \\
\hline Total & $0,58( \pm 0,03)$ & $0,47( \pm 0,01)$ & $0,47( \pm 0,01)$ \\
\hline BRS 225 & $-0,14( \pm 0,01)$ & $-0,32( \pm 0,01)$ & $-0,18( \pm 0,01)$ \\
\hline Azevém & $-0,18( \pm 0,01)$ & $-0,19( \pm 0,02)$ & $-0,21( \pm 0,02)$ \\
\hline Total & $0,68( \pm 0,01)$ & $0,49( \pm 0,01)$ & $0,61( \pm 0,02)$ \\
\hline \multicolumn{4}{|c|}{ Estatura } \\
\hline BRS Greta & $0,11( \pm 0,03)$ & $0,10( \pm 0,02)$ & $0,06( \pm 0,01)$ \\
\hline Azevém & $0,004( \pm 0,01)$ & $-0,06( \pm 0,02)$ & $-0,09( \pm 0,05)$ \\
\hline Total & $1,11( \pm 0,03)$ & $1,04( \pm 0,04)$ & $0,98( \pm 0,05)$ \\
\hline BRS Elis & $0,02( \pm 0,04)$ & $0,11( \pm 0,01)$ & $0,04( \pm 0,01)$ \\
\hline Azevém & $-0,01( \pm 0,03)$ & $0,04( \pm 0,01)$ & $0,06( \pm 0,04)$ \\
\hline Total & $0,98( \pm 0,03)$ & $1,10( \pm 0,02)$ & $1,10( \pm 0,04)$ \\
\hline BRS 225 & $0,11( \pm 0,03)$ & $0,10( \pm 0,02)$ & $0,06( \pm 0,01)$ \\
\hline Azevém & $0,004( \pm 0,01)$ & $-0,06( \pm 0,02)$ & $-0,09( \pm 0,05)$ \\
\hline Total & $1,11( \pm 0,03)$ & $1,04( \pm 0,04)$ & $0,98( \pm 0,05)$ \\
\hline \multicolumn{4}{|c|}{ Área foliar } \\
\hline BRS Greta & $-0,19( \pm 0,03)$ & $-0,17( \pm 0,01)$ & $-0,21( \pm 0,01)$ \\
\hline Azevém & $-0,21( \pm 0,01)$ & $-0,34( \pm 0,01)$ & $-0,43( \pm 0,02)$ \\
\hline Total & $0,55( \pm 0,01)$ & $0,40( \pm 0,03)$ & $0,63( \pm 0,03)$ \\
\hline BRS Elis & $-0,19( \pm 0,01)$ & $-0,21( \pm 0,01)$ & $-0,17( \pm 0,01)$ \\
\hline Azevém & $-0,21( \pm 0,01)$ & $-0,34( \pm 0,01)$ & $-0,43( \pm 0,02)$ \\
\hline Total & $0,60( \pm 0,02)$ & $0,45( \pm 0,01)$ & $0,40( \pm 0,03)$ \\
\hline BRS 225 & $-0,23( \pm 0,01)$ & $-0,32( \pm 0,01)$ & $-0,18( \pm 0,01)$ \\
\hline Azevém & $-0,21( \pm 0,01)$ & $-0,28( \pm 0,02)$ & $-0,19( \pm 0,03)$ \\
\hline Total & $0,55( \pm 0,01)$ & $0,40( \pm 0,03)$ & $0,63( \pm 0,03)$ \\
\hline \multicolumn{4}{|c|}{ Massa da matéria seca aérea } \\
\hline BRS Greta & $-0,18( \pm 0,01)$ & $-0,29( \pm 0,05)$ & $-0,15( \pm 0,01)$ \\
\hline Azevém & $-0,21( \pm 0,01)$ & $-0,25( \pm 0,01)$ & $-0,09( \pm 0,06)$ \\
\hline Total & $0,60( \pm 0,01)$ & $0,46( \pm 0,04)$ & $0,76( \pm 0,06)$ \\
\hline BRS Elis & $-0,22( \pm 0,02)$ & $-0,17( \pm 0,03)$ & $-0,15( \pm 0,01)$ \\
\hline Azevém & $-0,21( \pm 0,01)$ & $-0,35( \pm 0,01)$ & $-0,49( \pm 0,01)$ \\
\hline Total & $0,57( \pm 0,02)$ & $0,49( \pm 0,03)$ & $0,36( \pm 0,01)$ \\
\hline BRS 225 & $-0,18( \pm 0,01)$ & $-0,29( \pm 0,05)$ & $-0,15( \pm 0,01)$ \\
\hline Azevém & $-0,21( \pm 0,01)$ & $-0,25( \pm 0,01)$ & $-0,09( \pm 0,06)$ \\
\hline Total & $0,60( \pm 0,01)$ & $0,46( \pm 0,04)$ & $0,76( \pm 0,06)$ \\
\hline
\end{tabular}

Diferença significativa pelo teste $t(p \leq 0,05)$. Valores entre parênteses representam o erro-padrão da média. competidor (Almeida \& Mundstock, 2001). Outra explicação para que a cultura tenha sido mais competitiva que o azevém pode estar relacionada com a população de plantas que competiram com a cevada, já que as plantas daninhas apresentam maior habilidade competitiva quando em densidades populacionais elevadas e não individualmente (Fleck et al., 2003; Rigoli et al., 2008). Ressalta-se ainda que, em experimentos substitutivos, existe pouca evidência de haver mudanças qualitativas devido ao aumento da população, ou seja, a dominância de uma espécie sobre a outra raramente muda com a alteração da população (Cousens \& O’Neill, 1993).

Os resultados demonstram que os cultivares de cevada, de modo geral, apresentaram menor perda de $\mathrm{PR}$, comparativamente ao azevém, em todas as proporções de plantas associadas (Tabela 1), o que sugere que a cultura possui maior poder de supressão do que a planta daninha. Constataram-se aumentos na PRT da combinação quanto maiores foram as proporções de plantas correspondentes aos cultivares de cevada ou do competidor - situação significativa para ambas as variáveis estudadas. Esse comportamento mostra que as espécies são competitivas e que uma não contribui mais que o esperado para a produtividade total da outra (Roush et al., 1989). Os cultivares de cevada e o azevém exploraram o mesmo nicho ecológico e competiram pelos mesmos recursos do ambiente, apresentando diferenças em competitividade. Convém destacar ainda que, na mesma proporção de plantas (50:50), na associação dos cultivares de cevada com o competidor, a PRT, em geral, mostrou resultados inferiores aos das demais proporções (75:25 ou 25:75). Isso demonstra que as espécies são altamente competitivas em mesma densidade populacional e que competem severamente pelos mesmos recursos do meio, resultando em menor desenvolvimento delas, o que gera pouca contribuição para a PRT. Resultados similares foram constatados quando o milho competiu com o caruru (Christoffoleti \& Victória Filho, 1996) e a soja com o nabo (Biachi et al., 2006). Vários trabalhos também denotaram diferenças em termos de habilidade competitiva entre espécies aparentadas, como, por exemplo, entre arroz 
e capim-arroz (Agostinetto et al., 2008), entre trigo e azevém (Rigoli et al., 2008) e entre sorgo e sorgo-de-alepo ou entre sorgo e biótipo silvestre originado do sorgo cultivado (Hoffman \& Buhler, 2002).

O crescimento relativo dos cultivares BRS Greta, BRS Elis ou BRS 225 demonstrou, de modo geral, valores semelhantes entre si, porém diferenciados do competidor em mesma proporção de plantas, para todas as variáveis avaliadas (Figuras 1, 2, 3 e 4; Tabelas 1 e 2). Esses resultados permitem inferir que há efeito acentuado de características intrinsecas de cultivar sobre o azevém. Ressalta-se que a habilidade da cultura em interferir sobre a planta daninha é diferenciada, sendo isso atribuído principalmente à estatura e ao ciclo de desenvolvimento dos cultivares BRS Greta, BRS Elis ou BRS 225 (EMBRAPA, 2006). Esses

Tabela 2 - Diferenças entre plantas associadas ou não dos cultivares de cevada BRS Greta, BRS Elis e BRS 225 e de azevém para as variáveis afilhamento, estatura, área foliar e massa da matéria seca da parte aérea, aos 50 dias após a emergência das plantas

\begin{tabular}{|c|c|c|c|c|}
\hline $\begin{array}{l}\text { Proporção de plantas } \\
\text { (Cevada:competidor) }\end{array}$ & $\begin{array}{c}\text { Afilhos } \\
\text { (n⿳⺈ em cada } \\
\text { tratamento) }\end{array}$ & Estatura $(\mathrm{cm})$ & $\begin{array}{c}\text { Área foliar } \\
\left(\mathrm{cm}^{2}-\mathrm{n}^{\mathrm{o}} \mathrm{de}\right. \\
\text { plantas/tratamento })\end{array}$ & $\begin{array}{c}\text { Massa da } \\
\text { matéria seca } \\
\left(\mathrm{g}-\mathrm{n}^{\mathrm{o}} \mathrm{de}\right. \\
\text { plantas/tratamento })\end{array}$ \\
\hline \multicolumn{5}{|c|}{ Cultivar BRS Greta } \\
\hline $100: 0(\mathrm{~T})$ & 67,75 & 62,25 & $4.710,64$ & 25,75 \\
\hline $75: 25$ & 50,25 & 67,75 & $3.538,62$ & 25,99 \\
\hline $50: 50$ & 36,75 & 69,50 & $2.868,00$ & 18,34 \\
\hline $25: 75$ & 24,00 & 67,25 & $2.060,91$ & 15,74 \\
\hline $\mathrm{CV}(\%)$ & 10,22 & 6,61 & 8,23 & 6,58 \\
\hline \multicolumn{5}{|c|}{ Competidor azevém } \\
\hline $0: 100(\mathrm{~T})$ & 166,00 & 80,75 & $5.877,87$ & 26,56 \\
\hline $25: 75$ & 94,00 & 90,00 & $2.454,70$ & 10,44 \\
\hline $50: 50$ & 62,00 & 83,00 & $1.613,38$ & 8,52 \\
\hline $75: 25$ & 27,75 & 69,25 & 795,65 & 2,98 \\
\hline $\mathrm{CV}(\%)$ & 8,96 & 4,65 & 5,30 & 8,14 \\
\hline \multicolumn{5}{|c|}{ Cultivar BRS Elis } \\
\hline 100:0 (T) & 83,75 & 63,75 & $4.607,02$ & 33,35 \\
\hline $75: 25$ & 59,50 & 65,50 & $3.449,52$ & 23,61 \\
\hline $50: 50$ & 46,25 & 78,25 & $2.707,90$ & 22,33 \\
\hline $25: 75$ & 20,25 & 74,75 & $1.559,90$ & 13,39 \\
\hline $\mathrm{CV}(\%)$ & 15,74 & 7,60 & 6,54 & 9,06 \\
\hline \multicolumn{5}{|c|}{ Competidor azevém } \\
\hline $0: 100(\mathrm{~T})$ & 208,25 & 76,00 & $5.724,33$ & 28,25 \\
\hline $25: 75$ & 114,75 & 82,00 & $2.416,67$ & 9,68 \\
\hline $50: 50$ & 79,75 & 73,75 & $1.819,81$ & 8,53 \\
\hline $75: 25$ & 39,00 & 63,25 & 959,64 & 4,17 \\
\hline $\mathrm{CV}(\%)$ & 8,28 & 10,26 & 8,83 & 10,04 \\
\hline \multicolumn{5}{|c|}{ Cultivar BRS 225} \\
\hline $100: 0(\mathrm{~T})$ & 70,50 & 56,25 & $4.545,66$ & 31,84 \\
\hline $75: 25$ & 57,50 & 64,25 & $2.125,39$ & 24,03 \\
\hline $50: 50$ & 26,00 & 68,00 & $1.665,20$ & 13,28 \\
\hline $25: 75$ & 18,75 & 70,75 & $1.314,80$ & 12,54 \\
\hline $\mathrm{CV}(\%)$ & 12,48 & 7,43 & 7,19 & 15,09 \\
\hline \multicolumn{5}{|c|}{ Competidor azevém } \\
\hline $0: 100(\mathrm{~T})$ & 187,00 & 70,25 & $5.812,70$ & 26,07 \\
\hline $25: 75$ & 134,75 & 62,00 & $4.319,20$ & 22,85 \\
\hline $50: 50$ & 115,75 & 61,75 & $2.528,63$ & 13,00 \\
\hline $75: 25$ & 51,25 & 71,25 & 859,25 & 3,98 \\
\hline $\mathrm{CV}(\%)$ & 8,21 & 11,65 & 12,11 & 14,49 \\
\hline
\end{tabular}

Média difere da testemunha (T) pelo teste de Dunnett $(\mathrm{p} \leq 0,05)$. 
resultados corroboram os encontrados por Agostinetto et al. (2008) e Bianchi et al. (2006), cujos autores afirmaram a existência de variabilidade competitiva de acordo com o ciclo de desenvolvimento e as características intrínsecas de cada cultivar.

As variáveis morfológicas Afi, $\mathrm{AF}$ e MS, dos cultivares BRS Greta, BRS Elis ou BRS 225, foram reduzidas quando competiram com o azevém em todas as associações analisadas, independentemente da proporção de plantas na associação (Tabela 2). Quanto mais elevada a proporção do competidor na associação com os cultivares, maiores foram os danos às variáveis da cultura. Para Est, o efeito inverso ocorreu, ou seja, com o aumento da proporção de plantas do competidor nas simulações com os três cultivares de cevada, ocorreu aumento na variável. Isso ocorre pelo fato de que o aumento da competição entre a cevada e a planta daninha estimula os colmos a se alongarem em busca de luz. No azevém, verificouse redução no Afi, Est, AF e MSPA quando em igual ou menor proporção de plantas, comparativamente aos cultivares. Resultados similares a esses também foram constatados por Agostinetto et al. (2008).

Os resultados demonstram, para as variáveis Afi, $\mathrm{AF}$ e MS, que as maiores médias por planta da cultura ou mesmo do azevém foram obtidas quando estas se apresentavam em populações menores na associação em todas as combinações (Tabela 2). Assim, constata-se que a competição interespecífica é menos prejudicial para ambas as espécies envolvidas do que a competição intraespecífica. Ao trabalharem com trigo em competição com azevém, Rigoli et al. (2008) também observaram os mesmos efeitos denotados neste estudo. A competição afeta quantitativa e qualitativamente a produção, pois modifica a eficiência de aproveitamento dos recursos do ambiente, como água, luz, $\mathrm{CO}_{2}$ e nutrientes (Bianchi et al., 2006), estabelecendo-se entre a cultura e as plantas de outras espécies existentes no local. Essa competição ocorre também entre indivíduos de uma mesma espécie ou entre biótipos predominantes na área, conforme constatado por Ferreira et al. (2008), os quais verificaram que biótipos de azevém resistentes ao glyphosate possuem menor capacidade competitiva do que os suscetiveis.
Ressalta-se também que em uma comunidade de plantas há beneficio na competição pelos recursos para aquelas que se estabelecem primeiro, ou por características intrínsecas de cada cultivar quanto à habilidade competitiva (estatura, velocidade de crescimento, número de afilhos, entre outras).

Para as variáveis Afi, AF e MS, somente o cultivar BRS Elis demonstrou maior crescimento quando em competição com o azevém, conforme indicado pelo indice CR (Tabela 3). Ao se levar em conta a Est de plantas, observou-se que todos os cultivares avaliados foram mais competitivos que a espécie daninha. Contudo, quando foram utilizados os índices $\mathrm{K}$ e A, observou-se que o azevém foi mais competitivo que os cultivares de cevada, para as variáveis Afi, AF e MS (Tabela 3). Em todas as comparações verificaram-se diferenças entre os cultivares de cevada e de azevém, o que demonstra que ambos não se equivalem em termos de competição pelos recursos do ambiente, destacando-se que a planta daninha foi mais competitiva que os cultivares BRS Greta e BRS 225, mas menos competitiva que o BRS Elis. Utilizando os três índices para definir competitividade, foi verificado que o sorgo cultivado foi mais competitivo que Sorghum halepense (Hoffman $\&$ Buhler, 2002); que o nabo forrageiro foi mais competitivo que genótipos de soja (Bianchi et al., 2006); e que o capim-arroz sobressaiu em relação ao arroz irrigado (Agostinetto et al., 2008).

Interpretando conjuntamente as análises gráficas de variáveis relativas e suas significâncias em relação aos valores equivalentes (Figuras 1, 2, 3, 4; Tabela 1), às variáveis morfológicas (Tabela 2) e aos índices de competitividade (Tabela 3), em geral, constatou-se que há efeito de competição do azevém sobre os cultivares de cevada, demonstrando que essa espécie daninha possui elevada habilidade competitiva em relação à cultura. Ao explorarem basicamente o mesmo nicho ecológico, os cultivares de cevada e o azevém competem pelos mesmos recursos no tempo e/ou no espaço. Desse modo, as diferenças em termos de competitividade das espécies avaliadas podem ser devido ao fato de estas apresentarem características morfofisiológicas semelhantes. Resultados similares foram 
Tabela 3 - Índices de competitividade entre cultivares de cevada e competidor, expressos por competitividade relativa (CR), coeficientes de agrupamentos relativos $(\mathrm{K})$ e de agressividade (A), obtidos em experimentos conduzidos em séries substitutivas, aos 50 dias após a emergência das plantas

\begin{tabular}{|c|c|c|c|c|}
\hline Variável & $\mathrm{CR}$ & $\mathrm{K}_{\mathrm{x}}$ (cevada) & $\mathrm{K}_{\mathrm{y}}$ (competidor) & A \\
\hline \multicolumn{5}{|c|}{ Afilhamento } \\
\hline BRS Greta $\mathrm{x}$ azevém & $0,61( \pm 0,09)$ & $0,23( \pm 0,02)$ & $0,45( \pm 0,04)$ & $-0,13( \pm 0,03)$ \\
\hline BRS Elis $\mathrm{x}$ azevém & $1,46( \pm 0,12)$ & $0,38( \pm 0,02)$ & $0,24( \pm 0,02)$ & $0,08( \pm 0,02)$ \\
\hline BRS $225 \mathrm{x}$ azevém & $0,61( \pm 0,09)$ & $0,23( \pm 0,02)$ & $0,45( \pm 0,04)$ & $-0,13( \pm 0,03)$ \\
\hline \multicolumn{5}{|c|}{ Estatura } \\
\hline BRS Greta $\mathrm{x}$ azevém & $1,38( \pm 0,03)$ & $1,55( \pm 0,13)$ & $0,79( \pm 0,06)$ & $0,16( \pm 0,01)$ \\
\hline BRS Elis $\mathrm{x}$ azevém & $1,28( \pm 0,08)$ & $1,59( \pm 0,04)$ & $0,96( \pm 0,01)$ & $0,13( \pm 0,03)$ \\
\hline BRS $225 \mathrm{x}$ azevém & $1,38( \pm 0,03)$ & $1,55( \pm 0,13)$ & $0,79( \pm 0,6)$ & $0,16( \pm 0,01)$ \\
\hline \multicolumn{5}{|c|}{ Área foliar } \\
\hline BRS Greta $\mathrm{x}$ azevém & $0,85( \pm 0,07)$ & $0,23( \pm 0,02)$ & $0,28( \pm 0,03)$ & $-0,03( \pm 0,02)$ \\
\hline BRS Elis $\mathrm{x}$ azevém & $1,87( \pm 0,12)$ & $0,42( \pm 0,004)$ & $0,19( \pm 0,01)$ & $0,13( \pm 0,01)$ \\
\hline BRS $225 \mathrm{x}$ azevém & $0,85( \pm 0,07)$ & $0,23( \pm 0,02)$ & $0,28( \pm 0,03)$ & $-0,03( \pm 0,02)$ \\
\hline \multicolumn{5}{|c|}{ Matéria seca da parte aérea } \\
\hline BRS Greta $\mathrm{x}$ azevém & $0,86( \pm 0,22)$ & $0,28( \pm 0,07)$ & $0,33( \pm 0,02)$ & $-0,04( \pm 0,05)$ \\
\hline BRS Elis $x$ azevém & $2,22( \pm 0,17)$ & $0,51( \pm 0,06)$ & $0,18( \pm 0,007)$ & $0,18( \pm 0,02)$ \\
\hline BRS $225 \mathrm{x}$ azevém & $0,86( \pm 0,22)$ & $0,28( \pm 0,07)$ & $0,33( \pm 0,02)$ & $-0,04( \pm 0,05)$ \\
\hline
\end{tabular}

Diferença significativa pelo teste $\mathrm{t}(\mathrm{p} \leq 0,05)$. Valores entre parênteses representam o erro-padrão da média. $\mathrm{K}_{\mathrm{x}}$ e $\mathrm{K}_{\mathrm{y}}$ são os coeficientes de agrupamentos relativos do cultivar de cevada e do competidor, respectivamente.

observados em trabalhos que avaliaram a competitividade entre espécies com algum grau de semelhança (Hoffman \& Buhler, 2002; Rigoli et al., 2008; Agostinetto et al., 2008).

Desse modo, essas pesquisas tornam-se úteis para identificar qual a população ideal de planta daninha para se tomar a decisão de controle, desde que essa não venha a causar interferência negativa sobre a cultura. Ressalta-se também que o fluxo potencial de emergência do azevém por safra pode ser de aproximadamente 20.000 plantas $\mathrm{m}^{-2} \mathrm{em}$ áreas de monocultivo (Kissmann, 1997), o que pode ao longo dos anos aumentar muito a população dessa planta daninha nas lavouras em que infesta.

Os resultados permitem concluir que houve competição entre os cultivares de cevada BRS Greta, BRS Elis ou BRS 225 com o azevém, independentemente da proporção de plantas na associação, com redução no afilhamento, área foliar e massa seca da parte aérea dos competidores. Entre os cultivares, BRS Elis foi o mais competitivo com a espécie daninha em relação aos demais. Assim, fica evidente que o azevém é uma espécie daninha que necessita de controle mesmo quando presente em baixas populações nas lavouras de cevada.

\section{AGRADECIMENTO}

Ao Conselho Nacional de Desenvolvimento Científico e Tecnológico (CNPq-Brasil), pelo apoio financeiro e pelas concessões de bolsa.

\section{LITERATURA CITADA}

AGOSTINETTO, D. et al. Período crítico de competição de plantas daninhas com a cultura do trigo. Planta Daninha, v. 26, n. 2 , p. $271-278,2008$

ALMEIDA, L. A.; MUNDSTOCK, C. M. A qualidade da luz afeta o afilhamento em plantas de trigo, quando cultivadas sob competição. Ci. Rural, v. 31, n. 3, p. 401-408, 2001.

BIANCHI, M. A.; FLECK, N. G.; LAMEGO, F. P. Proporção entre plantas de soja e plantas competidoras e as relações de interferência mútua. Ci. Rural, v. 36, n. 5, p. $1380-1387,2006$

CRISTOFFOLETI, P. J.; VICTORIA FILHO, R. Efeitos da densidade e proporção de plantas de milho (Zea mays L.) e caruru (Amaranthus retroflexus L.) em competição.

Planta Daninha, v. 14, n. 1, p. 42-47, 1996 
COMPANHIA NACIONAL DE ABASTECIMENTO CONAB. Cevada - Brasil. Série Histórica de: área, produtividade e produção. Disponível em: $<$ http:// www.conab.gov.br> Acesso em: 27 jan. 2011.

COUSENS, R. Aspects of the design and interpretation of competition (interference) experiments. Weed Technol., v. 5, n. 3, p. 664-673, 1991.

COUSENS, R.; O’NEILL, M. Density dependence of replacement series experiments. Oikos, v. 66, n. 2, p. $347-352,1993$.

EMBRAPA - EMPRESA BRASILEIRA DE PESQUISA AGROPECUÁRIA. Indicações técnicas para a produção de cevada cervejeira nas safras de 2005/06. In: REUNIÃO ANUAL DE PESQUISA DE CEVADA, 25. Reunião... Passo Fundo: Embrapa Trigo, 2005/06. 102 p.

FOOD AND AGRICULTURE ORGANIZATION - FAO.

Disponível em: $<$ http://www.fao.org/economic/ess/ publications-studies/statistical-yearbook $>$. Acesso em: 20 jan 2011.

FERREIRA, E. A. et al. Distribuição de glyphosate e acúmulo de nutrientes em biótipos de azevém. Planta Daninha, v. 26, n. 1, p. 165-173, 2008.

FLECK, N. G. et al. Características de plantas de cultivares de arroz irrigado relacionadas à habilidade competitiva com plantas concorrentes. Planta Daninha, v. 21, n. 1, p. 97-104, 2003.

HARPER, J. L. The population biology of plants. London: Academic Press, 1977. 275 p.
HOLMAN, J. D. et al. Spring wheat, canola, and sunflower response to Persian darnel (Lolium persicam) interference. Weed Technol., v. 18, n. 3, p. 509-520, 2004.

HOFFMAN, M. L.; BUHLER, D. D. Utilizing Sorghum as a functional model of crop weed competition. I. Establishing a competitive hierarchy. Weed Sci., v. 50, n. 4, p. 466-472, 2002.

KISSMANN, K. G. Plantas infestantes e nocivas. 2.ed. São Paulo: BASF, 1997. Tomo I. 825 p.

NUNES, A.L. et al. Tolerância de espécies de inverno a herbicidas residuais. Sci. Agr., v. 8, n. 4, p. 443-448, 2007.

PITELLI, R. A. Interferência de plantas daninhas em culturas agrícolas. Inf. Agropec., v. 11, n. 129, p. 16-027, 1985.

RICHARDSON, M. J. Yield loss in barley associated with Sinapis arvensis L. (charlock) after continuous routine use of herbicide. Weed Res., v. 20, n. 5, p. 295-298, 1980.

RIGOLI, R. P. et al. Habilidade competitiva de trigo (Triticum aestievum) em convivência com azevém (Lolium multiflorum) ou nabo (Raphanus raphanistrum). Planta Daninha, v. 26, n. 1, p. 93-100, 2008.

ROUSH, M. L. et al. A comparison of methods for measuring effects of density and proportion in plant competition experiments. Weed Sci., v. 37, n. 2, p. 268-275, 1989.

STATISTICAL ANALYSIS SYSTEM - SAS. User's guide 4.ed. Cary: SAS Institute, 1989. 846 p.

SCURSONI, J. A.; SATORRE, E. H. Barley (Hordeum vulgare) and wild oat (Avena fatua) competition is affected by crop and weed density. Weed Technol., v. 19, n. 4, p. 790-795, 2005. 